Spread over ten years, the money will be distributed on the advice of the Nature Conservancy and a specially set up Teesdale Research Panel, under the chairmanship of Professor A. R. Clapham. It will, in fact, be best for Teesdale if this new found discretion can be maintained; sightseers are already said to have caused some damage to the flowers which make Cow Green such an unusual botanical site.

\section{Radioactive Dating and Low-Level Counting}

A symposium on "Radioactive Dating and Methods of Low-Level Counting" was held in Monaco during March 2-10, 1967. The meeting, which was sponsored by the International Atomic Energy Agency in cooperation with the Joint Commission on Applied Radioactivity (I.C.S.U.), was attended by about 160 scientists from twenty-six countries. It was the second in the series of symposia on "Radioactive Dating"- the first was held in Athens in 1962-and a wider range of topics was discussed than at the first.

The first two days were devoted almost exclusively to the geochemistry and cosmochemistry of radiocarbon with minor contributions to dating problems. Highlights of these topics include the expanding applications of bomb-produced radiocarbon to geochemical and geophysical processes, such as atmosphere-ocean exchange, and transport processes within the atmosphere. Of particular interest to those geologists and archaeologists who rely on carbon-14 dates was the extension of the bristlecone pine calibration of the radiocarbon time scale in the period 4100 B.c. -1500 B.c. Research continues on the possible use of the ${ }^{230} \mathrm{Th}$ to ${ }^{234} \mathrm{U}$ inequilibrium method for dating marine carbonates and its comparison with carbon-14 measurements.

Data were presented on short-lived nuclides in the meteorite which fell at 2.40 p.m. G.M.T. June 27, 1966, near Saint-Severin, Charente, France. Nuclides detected by $\gamma$-spectrometry included ${ }^{52} \mathrm{Mn},{ }^{48} \mathrm{~V},{ }^{51} \mathrm{Cr}$, ${ }^{56} \mathrm{Co},{ }^{60} \mathrm{Co},{ }^{54} \mathrm{Mn},{ }^{26} \mathrm{Al}$ and ${ }^{40} \mathrm{~K}$. Interest was aroused in the possible space erosion of certain iron meteorites without any definitive conclusions being reached.

Considerable progress has been made in "open" geological systems. Studies of the ratios ${ }^{208} \mathrm{~Pb}:{ }^{232} \mathrm{Th}$, ${ }^{207} \mathrm{~Pb}:{ }^{235} \mathrm{U}$ and ${ }^{206} \mathrm{~Pb}:{ }^{238} \mathrm{U}$ in cogenetic zircons indicated the hazards of "absolute age" determinations of minerals. Although ages determined in the usual manner are discordant, the data are significant when the transport of elements in the natural systems is being investigated. Similar studies have been performed on the dating of aragonitic shells by the ${ }^{230} \mathrm{Th}:{ }^{234} \mathrm{U}$ and ${ }^{231} \mathrm{~Pa}:{ }^{235} \mathrm{U}$ methods, where once more the system was "open" for the migration of uranium, and some success was reported with such materials. "Absolute Dating" by the ${ }^{87} \mathrm{Rb}:{ }^{87} \mathrm{Sr}$ and ${ }^{40} \mathrm{~K}:{ }^{40} \mathrm{Ar}$ methods was discussed. Here again it was evident that reported "ages" must be used with extreme care because of method uncertainties; for example, the problem of excess argon.

Observations of the existence of fossil $\alpha$-particle recoil tracks from uranium and thorium in samples of muscovite served to stimulate interest in the "fissiontrack" dating method. If these results are confirmed it is likely that a considerable improvement in the sensitivity of the method will accrue. The use of less conventional methods, such as thermoluminescence and electron spin resonance dating, was reported, and although the former is applicable to archaeological specimens the latter does not hold much promise at the present time.

\section{Digging up the Moon}

ON the eve of launch of the third lunar soft-landing Surveyor spacecraft Dr. W. H. Pickering, director of the Jet Propulsion Laboratory, discussed the results of the past two years' photographic missions to the Moon. The meeting, in London on April 7, was held by the British Interplanetary Society.

The completed Ranger series and the Surveyors and Lunar Orbiters now mid-way through their programmes have all been in support of the eventual Apollo manned lunar landing. Consequently their targets have been concentrated along a narrow equatorial belt of the Moon's face towards the Earth. Considerations of control and communications have determined that the Apollo landing site must lie within this zone. At first sight, the maria are the most promising regions.

A substantial body of information has been built up about the median maria by the three types of lunar survey craft launched from the United States. The once heretical view that the Moon shows geological activity is now taken for granted. It is now supposed that the floor of the Ocean of Storms (Procellarum), where both Surveyor 1 and Luna 9 landed, has a "topsoil" of relatively soft, friable material resembling a "just raked flowerbed" and able to support 5-10 pounds per square inch. "This is something you could walk on." Dr. Pickering estimated that this softish material goes down $3 \mathrm{ft}$., where a harder body rock may be encountered. To test this view, this month's Surveyor will carry a trenching tool on the end of an extendable arm and will attempt to dig a circular trench down to $4 \mathrm{ft}$ around the craft. It will, however, be aimed at a different target area. At present the choice lies between an equatorial site about $25^{\circ} \mathrm{W}$. and the Sinus Medii, the target for the abortive Surveyor 2.

As a result of the panoramic photo surveys carried out so far by the three Lunar Orbiters, several of the possible Apollo landing sites originally under consideration have now been eliminated. On closer inspection from a few miles high, some have proved much too broken up. Five candidates remain. Apart from the standard TV camera equipment, later Surveyorsa total of 8 is scheduled-will carry ancillary experiments such as a seismograph.

Dr. Pickering said that data so far had made the planners "very curious" about the lunar highlands. Some of the spacecraft pictures gave an impression that the highlands are being "sand-blasted". For the time being it seems there are no probes to spare from the practical task of finding a safe Apollo landing ground, and this is obviously not going to be in the highlands. The back of the Moon is also for the time being out of bounds, but the Orbiters have had enough film over from their primary tasks to survey most of the Moon's hidden face, and the resolution of the pictures is much better than that of the two Russian sets of distant views taken earlier. 